\title{
Association between idiopathic hearing loss and mitochondrial DNA mutations: A study on 169 hearing-impaired subjects
}

\author{
VALERIA GUARAN ${ }^{1}$, LAURA ASTOLFI $^{1}$, ALESSANDRO CASTIGLIONE $^{4}$, EDI SIMONI $^{1}$, \\ ELENA OLIVETTO ${ }^{1}$, MARCO GALASSO $^{3}$, PATRIZIA TREVISI $^{4}$, MICOL BUSI $^{2}$, \\ STEFANO VOLINIA $^{3}$ and ALESSANDRO MARTINI ${ }^{4}$ \\ ${ }^{1}$ Bioacoustics Research Laboratory, Department of Neurosciences, University of Padua, I-35129 Padua; \\ Departments of ${ }^{2}$ Audiology and ${ }^{3}$ Morphology and Embriology, University of Ferrara, I-44121 Ferrara; \\ ${ }^{4}$ ENT Surgery, Department of Neurosciences, University of Padua, I-35129 Padua, Italy
}

Received April 17, 2013; Accepted June 24, 2013

DOI: $10.3892 / \mathrm{ijmm} .2013 .1470$

\begin{abstract}
Mutations in mitochondrial DNA (mtDNA) have been shown to be an important cause of sensorineural hearing loss (SNHL). In this study, we performed a clinical and genetic analysis of 169 hearing-impaired patients and some of their relatives suffering from idiopathic SNHL, both familial and sporadic. The analysis of four fragments of their mtDNA identified several polymorphisms, the well known pathogenic mutation, A1555G, and some novel mutations in different genes, implying changes in the aminoacidic sequence. A novel sporadic mutation in $12 \mathrm{~S}$ rRNA $(M T-R N R I)$, not previously reported in the literature, was found in a case of possible aminoglycoside-induced progressive deafness.
\end{abstract}

\section{Introduction}

Hearing loss (HL) affects 1-3 of every 1,000 newborns; thus, it is one of the most common sensory disorders in humans (1). This condition is caused by environmental factors, such as noise or treatment with ototoxic drugs (e.g., aminoglycoside antibiotics) or genomic alterations. Hereditary HL occurs in the presence of defects either in the nuclear genome, as the $35 \mathrm{delG}$ mutation in the gene encoding connexin 26 (GJB2), or in mitochondrial DNA (mtDNA). Mutations in mtDNA have been shown to be responsible for both maternally inherited syndromic and non-syndromic HL (NSHL) and play a role in the predisposition to aminoglycoside-induced ototoxicity. Jacobs et al (2) demonstrated that in Italy, at least $5 \%$ of cases of post-lingual, non-syndromic hearing impairment may be attributed to mtDNA mutations. Furthermore, it has been estimated that up to $67 \%$ of patients with mtDNA disorders also

Correspondence to: Dr Valeria Guaran, Bioacoustics Research Laboratory, Department of Neurosciences, University of Padua, via G. Orus 2b, I-35129 Padua, Italy

E-mail: valeria.guaran@unipd.it

Key words: mitochondrial DNA, non-syndromic hearing loss, T961G, mitochondrial DNA variants, polymorphisms manifest sensorineural HL (SNHL) (3). This may be explained by the fact that cells of the cochlea have high oxidative phosphorylation demands, and are thus affected to a greater extent than other cells by a mitochondrial decrease in the protein synthesis rate provoked by mutations in mtDNA.

Non-syndromic SNHL associated with mtDNA mutations is generally progressive $(4,5)$, involving mainly higher frequencies (6-8) and is generally symmetric HL. The onset of HL usually occurs in childhood, is predominantly post-lingual and may be accompanied with vertigo (9) and tinnitus $(10,11)$. There is a high variability in severity ranging from normal hearing to profound deafness, even within families presenting similar genotypes (12-14); this may be due to the fact that the phenotypic effects are a result of several factors and can develop gradually. Some mtDNA variants, in particular in the MT-RNRI and $t R N A^{\operatorname{Ser}(U C N)}$ genes, have been identified in several cases as the main cause of SNHL, suggesting that these two loci in particular are hotspots for deafness-associated mutations.

The most commonly reported mutations known to cause HL are A1555G (15), 961delT (16-18), C1494T (19), A7445G (20,21), 7472insC (22,23) and A3243G (24,25). These variants together with the use of aminoglycosides or in association with other mutations, either mitochondrial or nuclear, can aggravate the condition of hearing impairment.

In particular, it has been documented that, even though the presence of the mutation, A1555G, itself may induce HL (15), this effect may be worsened in combination with aminoglycoside therapy, as this variant produces a modification in 12 rRNA, making its secondary structure more similar to the corresponding region of $E$. coli $16 \mathrm{~S}$ rRNA, thus much more vulnerable to the effects of this class of antibiotics (16).

mtDNA variants, as mutations, deletions or insertions, at position 961 in the same $M T-R N R l$ gene, have been found in patients with SNHL either with or without a history of aminoglycoside therapy $(26,27)$. The $T>G$ substitution in position 961 in particular, has been observed more frequently in hearing-impaired patients compared with controls; thus, it has been suggested to correlate with SNHL (28).

Taking into consideration that thus far, several mutations have been examined and many are yet to be discovered, in our study, we aimed to identify novel potentially pathogenic 
mtDNA variants and establish the frequency of the known mutations in our cohort of deaf patients.

\section{Patients and methods}

Patients. In collaboration with the Audiology Clinic at the Hospital of Ferrara,Ferrara, Italy we retrieved data on 169 patients suffering from hearing impairment without known aetiology and some of their close relatives. The present study was composed of 102 females and 67 males, with an average age of 20 years (ranging from 0 to 67 years). Their only clinical feature was HL and they did not present any syndromic sign or other clinical abnormalities, including muscular diseases, diabetes, visual dysfunction or neurological disorders. The analysis referred to the audiological tests data. In the audiometric tests, the severity of hearing impairment was defined by pure-tone threshold average (PTA) in frequencies: 500, 1,000, 2,000 and 4,000 Hz. $\mathrm{HL}$ of $<20 \mathrm{~dB}$ was considered as normal hearing, $21-40 \mathrm{~dB}$ mild HL, 41-70 dB moderate HL, 71-90 dB severe HL and $>90 \mathrm{~dB}$ profound HL. Written informed consent was provided from all study participants prior to enrollment. Any research involving human subjects was conducted in accordance with the ethical standards of all applicable national and institutional committees and with the World Medical Association's Helsinki Declaration.

Sequence analysis of mtDNA, secondary structure analysis and sequence conservation. Total DNA was extracted from peripheral blood using the Wizard Genomic DNA Purification kit from Promega (Madison, WI, USA). The analysis and search for the mutations in the genes coding for connexin 26 (GJB2), connexin 30 (GJB6) and pendrin (SLC26A4) were carried out by the Department of Medical Genetics at the Hospital of Ferrara.

From each subject, four regions corresponding to the mitochondrial genomes coding for 12S RNA (MT-RNRI), tRNA serine 1 (UCN) (MT-TS1), tRNA valine (MT-TV), tRNA leucine 1 (MT-TL1), tRNA aspartic acid (MT-TD) and part of 16S rRNA (MT-RNR2), NADH dehydrogenase subunit I (MT-NDI), cytochrome $c$ oxidase subunit I (MT-COI), cytochrome $c$ oxidase subunit II (MT-CO2) were PCR-amplified. The PCR products were analysed by direct sequencing in the ABI 3730XL or ABI 3100 sequencing machines at BMR Genomics (Padova, Italy). The sequence data were compared to the revised Cambridge Sequence (rCRS), GenBank accession no. NC_012920 (http:// www.ncbi.nlm.nih.gov/nuccore/NC_012920).

The presence and the nature of all identified nucleotide changes (polymorphisms, putative pathogenic variants, mutations) were confirmed through mitomap (http://mitomap. org/MITOMAP) and the Human Mitochondrial Genome Database (http://www.genpat.uu.se/mtDB/) which report published and unpublished data on human mtDNA variations and contain a comprehensive database of the complete human mitochondrial genomes, including sequences from GenBank (16,411 sequences with size $>14 \mathrm{kbp}$ ) and other sources.

In the subjects harbouring the mutations, A1555G, A3213G, C7792T and T961G, homo/heteroplasmy was determined by electrophoresis on a $1.2 \%$ agarose gel following enzymatic digestion as previously described (28).

The RNAfold software (http://rna.tbi.univie.ac.at/cgi-bin/ RNAfold.cgi) was used to predict the RNA secondary structure based on minimum energy requirements and base pair probability. The folding of sequences containing novel mutations was compared to the wild-type prediction.

The rCRS and the mitochondrial sequence of 18 different mammals [Gorilla gorilla, Cavia porcellus, Capra hircus, Bos Taurus, Macaca (fascicularis, sylvanus, mulatta, thibetana), Canis lupus familiaris, Felis catus, Equus asinus, Sus scrofa, Mus musculus, Rattus norvegicus, Pongo abelii, Pongo pygmaeus, Pan paniscus, Pan troglodytes] were aligned using the ClustalW2 sequence alignment program (http:// www.ebi.ac.uk/Tools/msa/clustalw2/) to analyse the conservation of the positions of the new sequence variants identified in our patients. We considered the variants conserved with a conservation rate $>50 \%$.

\section{Results}

The 169 subjects presented with idiopathic SNHL and no other symptoms. We performed a mutation analysis of four mtDNA fragments corresponding to the hot spots for HL. We detected mutations in GJB2 in 43 patients and excluded 18 of them from our analysis as they did not show any association with mtDNA variants.

Comparing the mitochondrial genomes to the rCRS, in our cohort of patients, we found 81 different sequence alterations (Table I), including HL-associated A1555G, putatively pathogenic T961G and five other mutations that have never been reported to date. Among the five novel mutations, we hypothesised that one in particular (G786A) may play a role in the onset of aminoglycoside-induced HL.

$A 1555 G$. Three genetically unrelated subjects harboured the homoplasmic A1555G mutation in the MT-RNR1 gene, a mtDNA variant that has been associated with deafness. The subjects were two females and one male with an average age of 47 years suffering from SNHL. The enzymatic digestion of the fragment showed homoplasmy in all cases. The phenotypes were different as one was congenitally deaf, and the other two had the onset of the symptoms at 5 and at 19 years, respectively; unfortunately, none of them could recall any previous exposure to aminoglycosides (Table II).

Audiometric examination in all the affected individuals showed a downsloping curve confirming the typical pattern of mitochondrial SNHL, which implicates the loss of high hearing frequencies (Fig. 1). One of these patients with severe progressive hearing impairment harboured two additional mutations whose pathogenicity has yet to be defined: $\mathrm{T} 3504 \mathrm{C}$, a rare variant in the gene coding for $M T-N D 1$; and C7471T, a very rare mtDNA variant located in the extraloop of $t R N A^{\operatorname{Ser}(U C N)}$.

T961G. Six patients harboured the mutation, T961G, in $M T-R N R 1$. The phenotypes, as well as the audiometric tests in our T961G cases, were quite disparate as we found two young sisters (mit26 and mit29) with a moderate hearing impairment, whose father and mother were normoacusic even though the latter had the same mtDNA variant. Mit51 showed postlingual asymmetric progressive HL and in addition to T961G, harboured an additional mutation close to it (C959T) with a low frequency in the databases. Mit116 presented with profound familial congenital SNHL. As for the last two patients, mit178 had hypoplasia of the cochlea and mit186 presented with 
Table I. mtDNA alterations detected and conservation.

\begin{tabular}{ccccc}
\hline & $\%$ hypoacusia & & Mitomap \\
& with no GJB2 & & $\%$ on \\
Hypoacusic & mutation & & mtDB \% & GenBank \\
$(\mathrm{n}=168)$ & $(\mathrm{n}=150)$ & Cons. & on 2704 & 16411
\end{tabular}

Polymorphism

\begin{tabular}{|c|c|c|c|c|c|}
\hline G709A & 18 & 12 & Yes & 16.4 & 13.79 \\
\hline T710C & 1 & 0.67 & No & 0.89 & 1.16 \\
\hline A750G & 166 & 100 & Yes & 99.18 & 97.64 \\
\hline G930A & 1 & 0.67 & No & 2.25 & 2.42 \\
\hline G951A & 3 & 2 & No & 0.29 & 0.61 \\
\hline $\mathrm{T} 1189 \mathrm{C}$ & 5 & 3.33 & Yes & 3.85 & 4.42 \\
\hline $\mathrm{T} 1243 \mathrm{C}$ & 6 & 4 & Yes & 2.11 & 1.44 \\
\hline A1438G & 163 & 100 & Yes & 96.89 & 94.99 \\
\hline $\mathrm{T} 1700 \mathrm{C}$ & 4 & 2.67 & No & 0.18 & 0.74 \\
\hline G1719A & 15 & 10 & No & 4.10 & 4.41 \\
\hline A1811G & 12 & 8 & No & 7.54 & 8.49 \\
\hline G1888A & 9 & 6 & No & 5.32 & 6.19 \\
\hline T3336C & 1 & 0.67 & Yes & 0.33 & 0.64 \\
\hline A3348G & 1 & 0.67 & Yes & 1.74 & 0.80 \\
\hline T3394C & 2 & 1.33 & Yes & 1.44 & 1.64 \\
\hline T3396C & 1 & 0.67 & No & 0.22 & 0.83 \\
\hline A3447G & 1 & 0.67 & Yes & 0.44 & 0.52 \\
\hline A3480G & 4 & 2.67 & Yes & 4.85 & 5.26 \\
\hline A3505G & 3 & 2 & No & 2.07 & 1.25 \\
\hline G3591A & 2 & 1.33 & No & 0.74 & 0.53 \\
\hline $\mathrm{T} 3644 \mathrm{C}$ & 1 & 0.67 & Yes & 0.48 & 0.67 \\
\hline G3666A & 1 & 0.67 & No & 2.15 & 2.14 \\
\hline G3705A & 1 & 0.67 & No & 1.15 & 1.21 \\
\hline A3720G & 1 & 0.67 & Yes & 0.70 & 0.65 \\
\hline T3847C & 1 & 0.67 & No & 0.26 & 0.74 \\
\hline G3915A & 7 & 4.67 & Yes & 0.81 & 1.41 \\
\hline G7337A & 2 & 1.33 & No & 0.55 & 0.97 \\
\hline G7521A & 3 & 2 & No & 5.62 & 5.45 \\
\hline A7768G & 4 & 2.67 & Yes & 2.22 & 2.16 \\
\hline G7805A & 1 & 0.67 & No & 1.37 & 0.86 \\
\hline G7853A & 1 & 0.67 & No & 1.66 & 1.15 \\
\hline T7961C & 2 & 1.33 & No & 0.18 & 0.72 \\
\hline G8027A & 1 & 0.67 & No & 2.14 & 3.22 \\
\hline \multicolumn{6}{|c|}{ Possible HL-associated mutations } \\
\hline T961G & 6 & 4 & No & 0.18 & 0.37 \\
\hline \multicolumn{6}{|c|}{ HL-associated mutations } \\
\hline A1555G & 3 & 2 & Yes & 0.44 & nd \\
\hline \multicolumn{6}{|c|}{ Novel mutations } \\
\hline C712A & 1 & 0.67 & Yes & nd & nd \\
\hline G786A & 1 & 0.67 & Yes & nd & nd \\
\hline A $3213 G$ & 1 & 0.67 & Yes & nd & nd \\
\hline $\mathrm{C} 7534 \mathrm{~T}$ & 1 & 0.67 & No & nd & nd \\
\hline A7746G & 1 & 0.67 & No & nd & nd \\
\hline \multicolumn{6}{|c|}{ Rare mutations } \\
\hline A644G & 1 & 0.67 & Yes & 0.04 & 0.07 \\
\hline $\mathrm{T} 721 \mathrm{C}$ & 2 & 1.33 & No & 0.18 & 0.24 \\
\hline $\mathrm{T} 742 \mathrm{C}$ & 1 & 0.67 & No & 0.07 & 0.06 \\
\hline A813G & 1 & 0.67 & No & 1.63 & 0.49 \\
\hline $\mathrm{C} 867 \mathrm{~T}$ & 1 & 0.67 & No & 0.04 & 0.03 \\
\hline A942G & 2 & 1.33 & No & 0.11 & 0.09 \\
\hline C959T & 1 & 0.67 & No & nd & 0.13 \\
\hline T980C & 2 & 1.33 & No & 0.51 & 0.46 \\
\hline A1118G & 1 & 0.67 & Yes & 0.04 & nd \\
\hline
\end{tabular}

Table I. Continued.

\begin{tabular}{|c|c|c|c|c|c|}
\hline & $\begin{array}{l}\text { Hypoacusic } \\
(\mathrm{n}=168)\end{array}$ & $\begin{array}{c}\% \text { hypoacusia } \\
\text { with no } G J B 2 \\
\text { mutation } \\
(\mathrm{n}=150)\end{array}$ & Cons. & $\begin{array}{c}\operatorname{mtDB} \% \\
\text { on } 2704\end{array}$ & $\begin{array}{c}\text { Mitomap } \\
\% \text { on } \\
\text { GenBank } \\
16411\end{array}$ \\
\hline T1119C & 1 & 0.67 & Yes & 0.96 & 0.45 \\
\hline T1193C & 1 & 0.67 & Yes & 0.29 & 0.26 \\
\hline $\mathrm{C} 1405 \mathrm{~T}$ & 2 & 1.33 & Yes & 0.04 & nd \\
\hline T1406C & 2 & 1.33 & Yes & 0.37 & 0.32 \\
\hline A1618G & 1 & 0.67 & Yes & 0.04 & 0.03 \\
\hline A1708T & 1 & 0.67 & Yes & 0.04 & 0.01 \\
\hline T3308C & 2 & 1.33 & Yes & 0.81 & 0.01 \\
\hline $\mathrm{C} 3342 \mathrm{~T}$ & 2 & 1.33 & No & 0.04 & 0.06 \\
\hline C3388A & 1 & 0.67 & Yes & 0.07 & 0.07 \\
\hline T3504C & 1 & 0.67 & No & nd & 0.12 \\
\hline $\mathrm{A} 3511 \mathrm{G}$ & 1 & 0.67 & No & 0.04 & 0.14 \\
\hline C3546A & 1 & 0.67 & Yes & 0.11 & 0.05 \\
\hline T3645C & 1 & 0.67 & No & 0.18 & 0.15 \\
\hline A3672G & 1 & 0.67 & Yes & 0.07 & 0.14 \\
\hline A3714G & 2 & 1.33 & Yes & 0.15 & 0.17 \\
\hline C3741T & 1 & 0.67 & No & 0.18 & 0.20 \\
\hline C3792T & 1 & 0.67 & No & nd & nd \\
\hline A3808G & 2 & 1.33 & Yes & 0.04 & 0.07 \\
\hline C3903T & 1 & 0.67 & Yes & 0.04 & nd \\
\hline C3936T & 1 & 0.67 & Yes & 0.07 & 0.04 \\
\hline $\mathrm{A} 7385 \mathrm{G}$ & 1 & 0.67 & Yes & 0.63 & 0.40 \\
\hline T7440G & 1 & 0.67 & No & nd & nd \\
\hline $\mathrm{C} 7471 \mathrm{~T}$ & 1 & 0.67 & No & nd & 0.04 \\
\hline G7642A & 1 & 0.67 & No & 0.30 & 0.25 \\
\hline $\mathrm{T} 7645 \mathrm{C}$ & 2 & 1.33 & No & 0.22 & 0.29 \\
\hline $\mathrm{T} 7705 \mathrm{C}$ & 2 & 1.33 & No & 0.18 & 0.40 \\
\hline $\mathrm{A} 7717 \mathrm{G}$ & 1 & 0.67 & Yes & nd & nd \\
\hline A7720G & 1 & 0.67 & Yes & nd & 0.01 \\
\hline $\mathrm{C} 7792 \mathrm{~T}$ & 1 & 0.67 & Yes & nd & 0.04 \\
\hline G7830A & 1 & 0.67 & No & 0.15 & 0.10 \\
\hline $\mathrm{C} 7873 \mathrm{~T}$ & 1 & 0.67 & No & 0.15 & 0.12 \\
\hline G7984A & 1 & 0.67 & No & 0.07 & 0.07 \\
\hline A8014T & 1 & 0.67 & No & 0.15 & 0.32 \\
\hline
\end{tabular}

mtDNA, mitochondrial DNA; HL, hearing loss; nd, not determined; Cons., conserved.

progressive bilateral HL, which was later diagnosed as partial trisomy of chromosome $6 \mathrm{p}$.

We defined the homoplasmy in all of the cases, with the exception of mit51 whose state could not be determined as the presence of the other mutation in position 959 prevented the AciI restriction enzyme digestion. The comparison of the RNA secondary structure determined by this mutation shows a clear difference with the wild-type one (Fig. 2).

Novel mutations. We detected novel sequence variants not present in the literature or in mitochondrial databases (Table III), including C712A and the heteroplasmic G786A in MT-RNR1, A3213G in MT-RNR2, C7534T in the D-loop of TRND (tRNAAsp) and in the MT-CO2 gene, A7746G, which produces an aminoacidic change in translation. All the mutations were recorded in mitomap (http:/www.mitomap.org/bin/ 


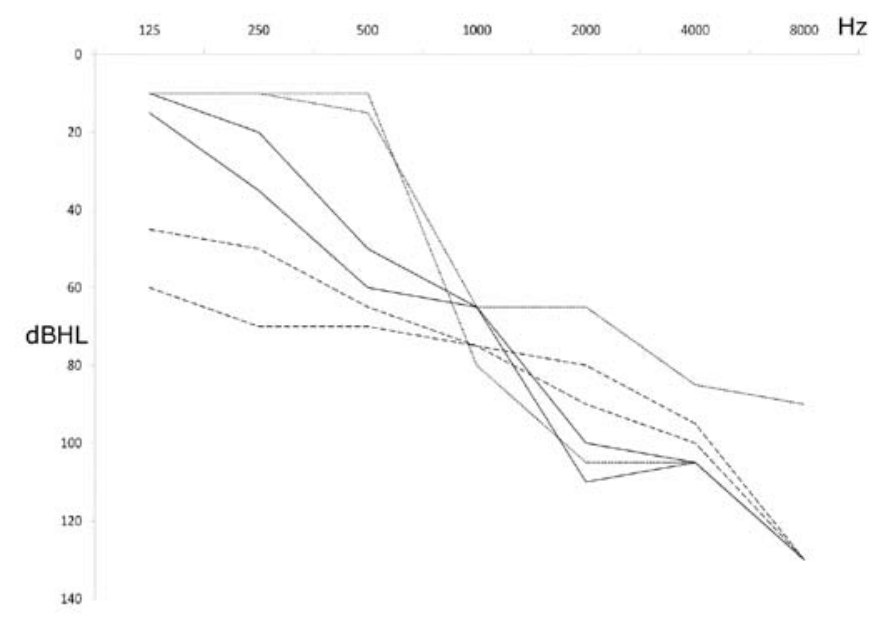

Figure 1. Superimposed audiograms of the three patients with A1555G mutation showing a downsloping trend corresponding to high frequency hearing loss. Hearing measured in decibels Hearing Level (dBHL), frequency in hertz (Hz).

view.pl/MITOMAP/VariantSubmissionList) and numbered from 20111230001 onwards. In a phylogenetic analysis, we compared the human nucleotide variants with other 18 different mammals and found a conservation rate of $>50 \%$ for variants 712, 786 and 3213 .

Among the novel mutations, we particularly considered the heteroplasmic G786A in mit7, a 39-year-old female. Her parents and sister were normoacusic and did not harbour any mutations either in mtDNA or in HL-associated genes. She suffered from asymmetric progressive SNHL and had been treated with streptomycin in her childhood. In our alignment analysis, position 786 in the $M T-R N R l$ gene was quite conserved (14/18); moreover, the mutated secondary structure prediction showed to be different compared to the wild-type one (Fig. 2).

In $M T-R N R 1$ we also found the mutation, $\mathrm{C} 712 \mathrm{~A}$, which may have an effect on HL as the site shows a $100 \%$ conservation even if no differences in the RNA structure of the gene are detectable. The patient harbouring this variant, a 13-year-old subject with mild SNHL (mit184), harboured two additional mutations of A1811G: a polymorphism and a quite rare $\mathrm{C}>\mathrm{A}$ mutation in the evolutionarily conserved position 3546 in the MT-ND1 gene.

A3213G in MT-RNR2 was detected in a young girl from Morocco harbouring several other variants (A3348G, G3591A, A3714G, G7642A and G7805A) with congenital profound SNHL. This was conserved and had a different RNA structure.

Mit145 harboured C7534T in the D-loop of $t R N A A s p$ together with G709A and the rare A8014T mutation in $M T-C O 2$. The other novel variant, $\mathrm{A} 7746 \mathrm{G}$, detected in the $M T$-CO2 gene, not conserved, was found in a 5-year-old boy also harbouring the T980C variant in $M T-R N R 1$. A7746G presents a missense mutation with the aminoacidic change Asn $>$ Ser in the subunit of cytochrome $c$ oxidase (complex IV).

Low frequency mutations. We identified several other variants that may be associated with hearing impairment, presenting a low frequency in mtDB and mitomap (Table IV). Among these, we preferably considered the mutations in subjects presenting audiograms compatible to a mitochondrial mutation HL diagnosis, in conserved positions and with a frequency $<0.05 \%$, such
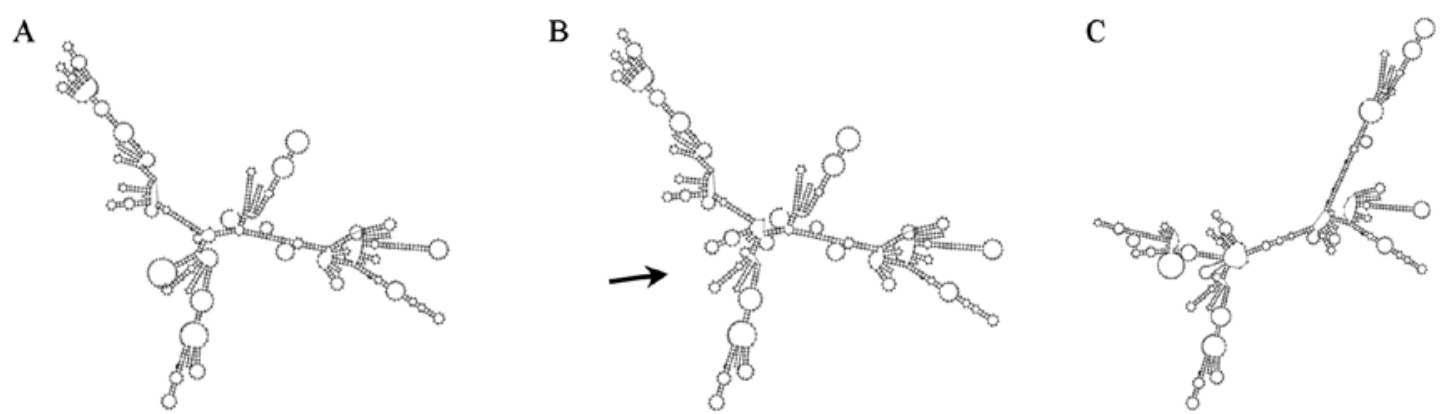

Figure 2. Differences in the predicted MT-RNR1 RNA secondary structure: (A) wild-type, (B) with the T961G mutation, (C) with the novel G786A mutation.

Table II. Patients harbouring the hearing loss-associated A1555G mutation.

\begin{tabular}{|c|c|c|c|c|c|c|c|c|c|c|c|c|c|}
\hline Patient & Gender & $\begin{array}{c}\text { Age } \\
\text { (years) }\end{array}$ & $\begin{array}{l}\text { Homo/ } \\
\text { hetero } \\
\text { plasmy }\end{array}$ & $2 d$ & $G J B 2$ & GJB6 & SLC26A4 & $\begin{array}{l}\text { Age of } \\
\text { onset } \\
\text { (years) }\end{array}$ & $\begin{array}{c}\text { PTA } \\
\mathrm{dx}\end{array}$ & $\begin{array}{l}\text { PTA } \\
\text { sn }\end{array}$ & $\begin{array}{c}\text { Family } \\
\text { history } \\
\text { of HL }\end{array}$ & $\begin{array}{c}\text { Other } \\
\text { mtDNA } \\
\text { mutations }\end{array}$ & $\begin{array}{l}\text { Type of } \\
\text { line in } \\
\text { Fig. } 1\end{array}$ \\
\hline Mit76 & $\mathrm{F}$ & 47 & Homo & Yes & wt & wt & wt & 5 & 80 & 81.2 & No, sporadic & $\begin{array}{l}\text { C7471T; } \\
\text { T3504C }\end{array}$ & Continuous \\
\hline Mit114 & $\mathrm{F}$ & 44 & Homo & Yes & wt & wt & wt & 19 & 56.2 & 75 & No, sporadic & No & Dotted \\
\hline Mit140 & M & 50 & Homo & Yes & wt & wt & wt & At birth & 80 & 82.5 & nd & No & Dashed \\
\hline
\end{tabular}

2d, differences in the secondary structure; PTA, pure-tone threshold average; dx, right; sn, left; HL, hearing loss; mtDNA, mitochondrial DNA; F, female; M, male; wt, wild-type; nd, not determined. 
as: i) the mutation $\mathrm{A}>\mathrm{G}$ in the conserved position $644(0,04 \%$ in $\mathrm{mtDB}$ ) in $M T-T F$, located in the acceptor stem of tRNAPhe. $644 \mathrm{~A}>\mathrm{G}$ found in a 13-year-old girl with SNHL, harbouring the polymorphisms, G709A, G1888A and C7873T; ii) T721C in MT-RNR1. This 36-year-old female had progressive HL which began at age 22; the RNA structure though did not seem to differ from the wild-type one; in fact, we eventually found the same mutation in a 34-year-old male heterozygotic for connexin 26 $35 \mathrm{delG}$ who was normoacusic; iii) T1119C in MT-RNRI found in mit110: a 36-year-old patient with progressive post-lingual bilateral SNHL which began at age 33; the RNA showed a different structure; iv) $\mathrm{C} 3342 \mathrm{~T}$ in the $N D 1$ gene in two deaf sisters harbouring both the additional mutation T7961C; v) A3808G a mutation in a conserved site found in two sisters with audiograms compatible to mitochondrial deafness; vi) A3847G in a case of a 37-year-old female whose mild sporadic hearing impairment began in her thirties; vii) A7720G in MT-CO2 in a 3-year-old subject presenting with mild progressive hearing impairment; viii) C7792T in MT-CO2, observed in a 42-yearold male with progressive hearing impairment which began in his twenties, presenting with moderate to severe symmetric impairment confirmed by a downward overlapping audiogram; ix) G7830A G7984A together with G709A and G1888A in a 45-year-old female with moderate $\mathrm{HL}$ at high frequencies.

Connexin 26 and mtDNA mutations. We searched for a correlation between mutations in connexin 26 and mtDNA mutations. Eighteen patients only harboured mutations in the $G J B 2$ gene and 25 of them harboured both the GJB2 and mtDNA variants (10 of whom were homozygotic for $35 \mathrm{delG}$ ).

In our subjects, we noticed a higher presence of the G3915A polymorphism, as 5 out of the total 7 probands with this polymorphism in NDI were associated with GJB2 mutations. In two siblings with SNHL and $35 \mathrm{delG} / 35 \mathrm{delG}$ in $G J B 2$, we identified the missense mutation, T3308C (Met>Thr), at the highly conserved amino acid position 1 in $M T-N D 1$. Among the patients with homozygotic $35 \mathrm{delG}$ in $G J B 2$ we found some rare mutations that may worsen their condition of hearing impairment (Table V). The mutations found were A3447G, C3903T, A7717G and G8027A, all in conserved positions in the genes $M T-N D 1$ and $M T-C O 2$. In the literature these were found to be more involved in Leber's hereditary optic neuropathy (LHON) than in HL. Another patient homozygotic for 35delG showed two additional variants: the missense mutation, A3505G, causing the Thr>Ala substitution in MT-NDI and the conserved T1243C mutation in the MT-RNRl gene.

\section{Discussion}

In the present study, we analysed four fragments of mtDNA in 169 subjects with non-syndromic SNHL, both familial and sporadic without a clear aetiology. We compared our data with the DNA of some of their relatives who were normoacusic in order to define whether the mutations were sporadic or genetically transmitted. We also considered the mutations in the GJB2, GJB6 and SLC26A4 genes which are recognised to be among the most frequent causes of hearing impairment. In total, 43 patients harboured GJB2 mutations and 18 were affected by $G J B 2$ mutations only (no mtDNA mutations).We thus decided to exclude this group from our analysis. 


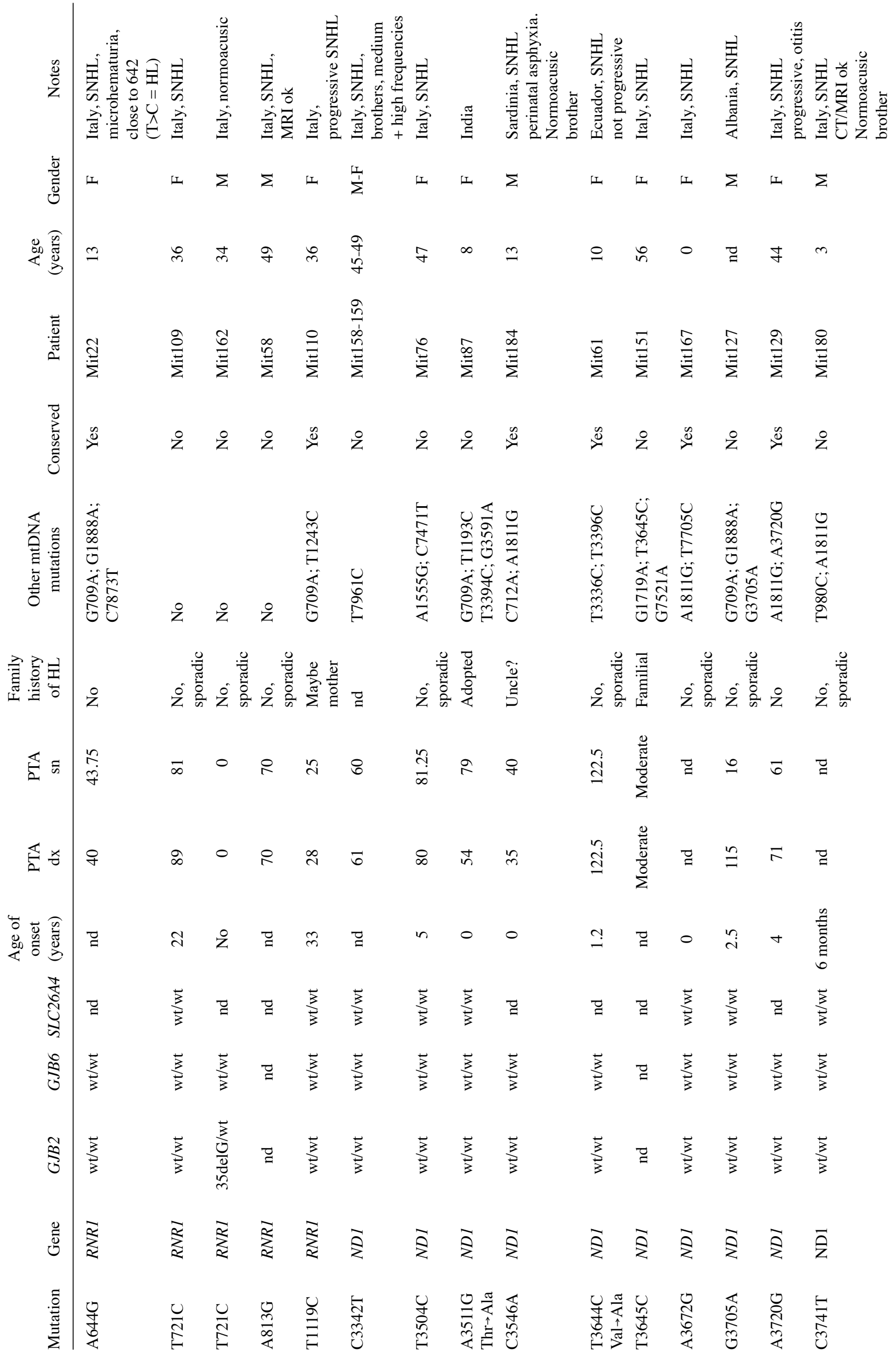




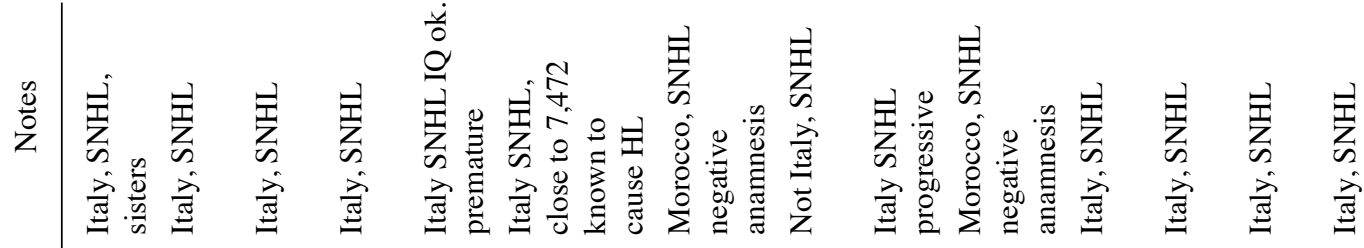

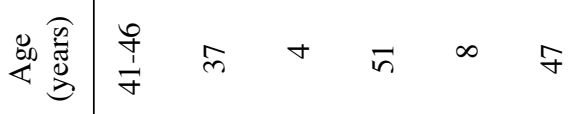

$+\infty$ \& $\frac{7}{4}+\frac{d}{4}$

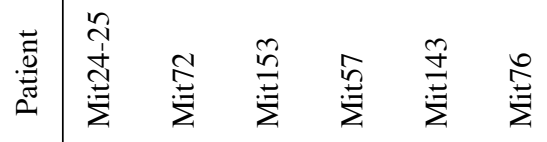

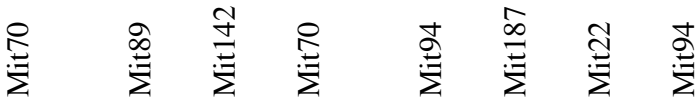

?

离 $\lesssim$


$\stackrel{\circlearrowright}{2} \stackrel{0}{2}$

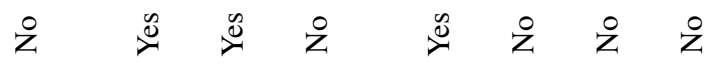

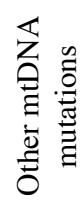

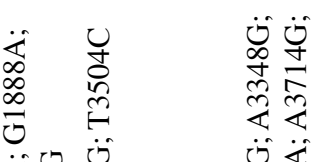

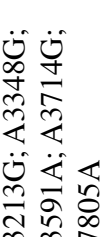

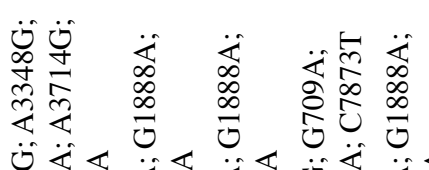

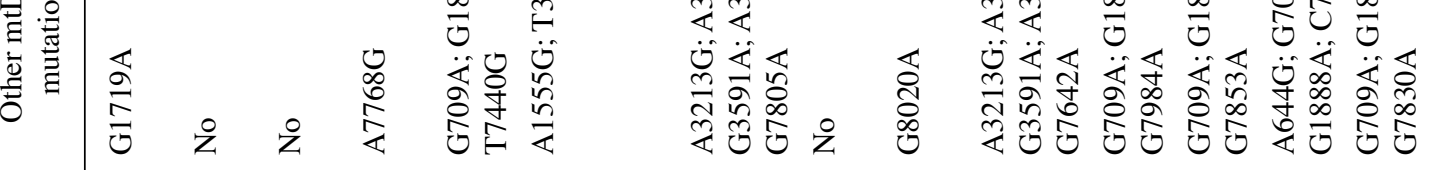

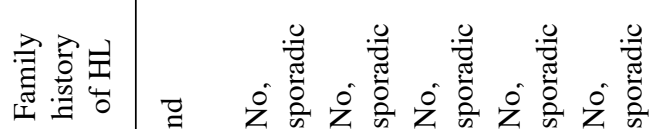

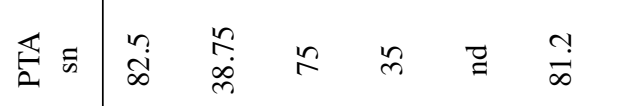

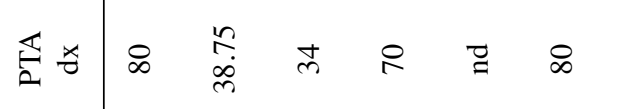
$\curvearrowleft$

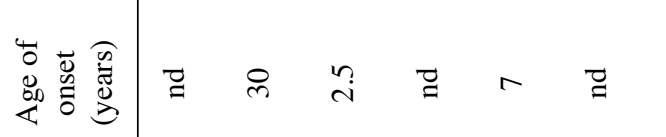

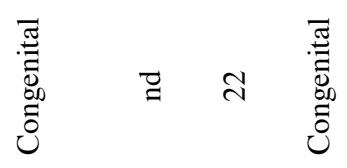

营

is

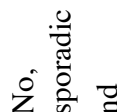


Table V. mtDNA and GJB2 mutations.

\begin{tabular}{|c|c|c|c|c|}
\hline Sample & $\begin{array}{l}\text { mtDNA } \\
\text { mutation }\end{array}$ & Gene & GJB2 & Notes \\
\hline Mit1-2 & $\mathrm{C} 1405 \mathrm{~T}$ & RNR1 & $\begin{array}{l}\text { 35delG/ } \\
\text { 35delG }\end{array}$ & $\begin{array}{l}\text { Severe SNHL, } \\
\text { homozygous twins }\end{array}$ \\
\hline Mit46-47 & $\mathrm{T} 3308 \mathrm{C}$ & ND1 & $\begin{array}{l}\text { 35delG/ } \\
\text { 35delG }\end{array}$ & $\begin{array}{l}\text { Mild-moderate } \\
\text { SNHL, brothers }\end{array}$ \\
\hline Mit73 & $\begin{array}{l}\text { A3447G; } \\
\text { G8027A }\end{array}$ & $\begin{array}{l}\mathrm{ND} 1 \\
\mathrm{CO} 2\end{array}$ & $\begin{array}{l}\text { 35delG/ } \\
\text { 35delG }\end{array}$ & $\begin{array}{l}\text { Profound SNHL, } \\
\text { familial }\end{array}$ \\
\hline Mit74 & G3915A & ND1 & $\begin{array}{l}\text { 35delG/ } \\
\text { 35delG }\end{array}$ & SNHL \\
\hline Mit135 & $\mathrm{T} 7645 \mathrm{C}$ & $\mathrm{CO} 2$ & $\begin{array}{l}\text { 35delG/ } \\
\text { 35delG }\end{array}$ & Profound SNHL \\
\hline Mit154 & $\begin{array}{l}\text { T1243C; } \\
\text { A3505G; } \\
\text { C3792T }\end{array}$ & $\begin{array}{l}\text { RNR1; } \\
\text { ND1 }\end{array}$ & $\begin{array}{l}\text { 35delG/ } \\
\text { 35delG }\end{array}$ & Profound SNHL \\
\hline Mit185 & $\begin{array}{l}\text { A942G; } \\
\text { T3394C }\end{array}$ & $\begin{array}{l}\text { RNR1; } \\
\text { ND1 }\end{array}$ & $\begin{array}{l}\text { 35delG/ } \\
\text { 35delG }\end{array}$ & $\begin{array}{l}\text { Moderate SNHL, } \\
\text { progressive }\end{array}$ \\
\hline Mitpds7 & $\begin{array}{l}\text { C3903T; } \\
\text { A7717G }\end{array}$ & $\begin{array}{l}\mathrm{ND} 1 \\
\mathrm{CO} 2\end{array}$ & $\begin{array}{l}\text { 35delG/ } \\
\text { 35delG }\end{array}$ & $\begin{array}{l}\text { SNHL, congenital, } \\
\text { familial }\end{array}$ \\
\hline Mit4 & G3915A & ND1 & $\begin{array}{l}\text { L90P/ } \\
\text { M34T }\end{array}$ & SNHL, congenital \\
\hline Mit5 & G3915A & ND1 & $\begin{array}{l}\text { 35delG/ } \\
\text { L90P }\end{array}$ & SNHL, congenital \\
\hline Mit6 & G3915A & ND1 & $\begin{array}{l}\text { 35delG/ } \\
\text { L90P }\end{array}$ & SNHL, congenital \\
\hline Mit32 & G1719A & RNR2 & 35delG/wt & $\begin{array}{l}\text { SNHL, } \\
\text { progressive, } \\
\text { familial }\end{array}$ \\
\hline Mit49 & $\begin{array}{l}\text { T1189C; } \\
\text { A1811G; } \\
\text { A3480G }\end{array}$ & $\begin{array}{l}\text { RNR1; } \\
\text { RNR2; } \\
\text { ND1 }\end{array}$ & $\mathrm{R} 127 \mathrm{H} / \mathrm{wt}$ & $\begin{array}{l}\text { Profound SNHL, } \\
\text { familial, } \\
\text { onset at age } 4\end{array}$ \\
\hline Mit83-115 & G7521A & TD & $\mathrm{L} 90 \mathrm{P} / \mathrm{wt}$ & $\begin{array}{l}\text { EVA, transmissive } \\
\text { HL, onset at age } 3 \text {, } \\
\text { brothers }\end{array}$ \\
\hline Mit123 & G3915A & ND1 & M34T/wt & Moderate SNHL \\
\hline Mit133 & $\begin{array}{l}\text { A1811G; } \\
\text { A3480G }\end{array}$ & $\begin{array}{l}\text { RNR2; } \\
\text { ND1 }\end{array}$ & $\begin{array}{l}\text { 35delG/ } \\
\text { R184P }\end{array}$ & $\begin{array}{l}\text { Profound SNHL, } \\
\text { congenital }\end{array}$ \\
\hline Mit139 & $\begin{array}{l}\text { C959T; } \\
\text { G1719A }\end{array}$ & $\begin{array}{l}\text { RNR1; } \\
\text { RNR2 }\end{array}$ & $\mathrm{wt} / 35 \mathrm{delG}$ & Normoacusic \\
\hline Mit145 & $\begin{array}{l}\text { G709A; } \\
\text { C7534T; } \\
\text { A8014T }\end{array}$ & $\begin{array}{l}\text { RNR1; } \\
\text { TD; } \\
\text { CO2 }\end{array}$ & wt/del120E & Normoacusic \\
\hline Mit155 & A7768G & $\mathrm{CO} 2$ & wt/M34T & SNHL, sisters \\
\hline Mit156 & A7768G & $\mathrm{CO} 2$ & $\begin{array}{l}\text { 35delG/ } \\
\text { M34T }\end{array}$ & SNHL, sisters \\
\hline Mit162 & $\mathrm{T} 721 \mathrm{C}$ & RNR1 & 35delG/wt & Normoacusic \\
\hline
\end{tabular}

mtDNA, mitochondrial DNA; HL, hearing loss; SNHL, sensorineural HL; wt, wild-type; EVA, enlarged vestibular aqueduct.

The hearing-impaired patients showed a wide range of penetrance, severity and age-at-onset of HL. We searched for mutations in the regions corresponding to the hotspots for deafness: the MT-RNR1 and the MT-TS1 genes, as the presence of mutations in these two genes in particular, is known to cause both syndromic and non-syndromic forms of hearing impairment; we also focused on the region of MT-TL1 as previous studies report its possible role in non-syndromic disease (29). In order to establish the potential pathogenicity of the mutations encountered, we analysed the evolutionary conservation comparing our sequences to those of other organisms. Furthermore, considering that the biological functions of 16S rRNA and tRNAs and other structural RNAs are dictated by their three dimensional structures, we analysed the possible RNA secondary structure of the mutated samples and predicted the folding using the Vienna RNA package. Our aim was to detect and correlate the frequency of mtDNA alterations in the cases of deafness showing the typical audiological manifestations of mitochondrial SNHL.

In our cohort of patients, we identified three subjects harbouring the A1555G mutation. This mutation in the $M T-R N R 1$ gene is one of the most common mtDNA variants associated with both non-syndromic progressive SNHL and aminoglycoside-induced SNHL. Sequence analysis of the $M T-R N R 1$ gene in our subjects identified three genetically unrelated individuals harbouring the $\mathrm{A} 1555 \mathrm{G}$ mutation who showed the typical mitochondrial HL audiometric features. The incidence of the mutation in hypoacusic subjects was $2 \%$, a little lower than the one recognised by Berrettini et al (29) in 2008, but similar to the data presented in the studies by Jacobs et al (2) and Lingala et al (30). We could not state if the use of aminoglycosides had any effect on these subjects as they could not recall any exposure to antibiotics in the past; however, one of these patients with severe and progressive HL harboured a novel mutation in position 7471 in $t R N A^{\operatorname{Ser}(U C N)}$, close to position 7472 , which has shown to cause both syndromic and non-syndromic deafness (31), suggesting that this variant somehow functions as a modifier, in synergy with the primary mutation, thus modulating its phenotypic manifestations as observed for other tRNA mutations (32).

We identified another mutation in the MT-RNR1 gene: seven patients harboured the T961G mutation with a frequency corresponding to data reported in the literature. Its pathogenicity is quite controversial: the mutations at position 961 have been detected in subjects affected by aminoglycoside-induced NSHL. The delT961Cn mutation is more frequent in Caucasian and Asian subjects $(16,26,27,33)$, as well as the $961 \mathrm{C}$ insertion $(17,19,27,28)$, T961C mutation in Chinese subjects (4) and T961G mutation in the Caucasian population (17). In a previous study, Li et al (28) found the T961G substitution in 5/164 hearing-impaired paediatric patients of Caucasian descent without a history of exposure to aminoglycoside, while the 226 Caucasian and 324 Chinese control subjects did not harbour this mutation; thus, it was hypothesised that this variant may be associated with SNHL. In contrast to these results indicating a possible pathogenic nature of the mutations around position 961 in NSHL and aminoglycosideinduced HL, Herrnstadt $e t$ al stated that it could be a typical polymorphism of the $\mathrm{H} 2$ haplogroup (34). The localization of position 961 is at the C-cluster of the region between loop 21 and 22 of MT-RNRI (35); compared with A1555G this region is not evolutionarily conserved and is in fact highly polymorphic in mammalian interspecies comparisons. Its function 
is not well defined; in particular, its pathogenic mechanisms of action in the predisposition of carriers to aminoglycoside toxicity remain unclear $(17,36)$. Elstner et al performed a single nucleotide polymorphism (SNP) analysis of the nucleotide 961 in a control group of 320 German samples, finding six $\mathrm{T}>\mathrm{C}$ and five $\mathrm{T}>\mathrm{G}$ nucleotide changes (37). Thus, the effects of this mutation have yet not been defined; we confirmed this mutation in our screening; six out of seven patients with T961G showed variable degrees of hearing impairment, suggesting at least a minor role in the HL onset; however, at the same time the mother of two hearing-impaired children harbouring the same mutation did not present with HL. Thus, it can be hypothesised that $\mathrm{T} 961 \mathrm{G}$ is either a polymorphism, or a pathogenic mutation with an extremely low penetrance.

One of the subjects in our cohort of patients harboured a novel mutation in position 786 in MT-RNRl. She did not harbour any other mutations in the genes usually associated with HL or any malformations. This alteration, in our opinion, could be the reason of her HL since its conserved site in the hotspot gene for HL and also as the RNA structure shows a clearly different folding compared with the wild-type one, suggesting a possible malfunctioning of the ribosome. From a clinical point of view, the patient presented with sporadic progressive SNHL with post-lingual onset; her audiometry was compatible with mitochondrial-associated HL and the fact that she was treated with aminoglycosides in the past confirms our hypothesis.

In our patient cohort, some other novel mtDNA variants in genes that are not usually involved in HL or have an association with other pathological conditions were recorded, though their exact role is unclear; thus, they should be investigated, further studied and compared with new cases.

We suggest that some of the rare mutations harboured by patients with audiometric data compatible with a mitochondrial HL are possible candidates for genetic risk factors of NSHL. Among these, we considered T1119C in MT-RNRI. We suggest that this variant detected in 36-year-old female may be responsible for her mild progressive bilateral SNHL, which began three years earlier. T1119C, already found in four subjects suffering from hearing impairment by Li et al (4), located in a conserved site and presenting with a different RNA structure, may be the cause of HL at high frequencies, confirmed by an audiogram. It should be noted that the late onset and gradual worsening of the impairment may reflect the tendency of the mitochondrion to accumulate mutations with aging due to its genomic instability.

Of note, we observed the non-pathogenicity of the T721C mutation in MT-RNRl that we thought could be responsible for the progressive HL of a 36-year-old female which began at age 22 . In fact, we eventually detected the same mutation in a 34 -year-old male heterozygotic for connexin $2635 \mathrm{delG}$ who was normoacusic.

In patients harbouring mutations in the most common HL-associated genes (connexin 26), we focused on the mtDNA mutations, in particular $\mathrm{T} 3308 \mathrm{C}$, which results in a change in the initiation codon of NADH dehydrogenase. In a study on mutant cells, Li et al (38). demonstrated that T3308C induces a significant decrease in the levels of $M T-N D 1$, resulting in a decreased complex I activity; furthermore, the T3308C mutation may also alter the hydrophobicity and antigenicity of the N-terminal peptide of $M T$-NDl (39). These facts suggest that a combination of a mtDNA mutation with other genomic DNA mutations may increase the penetrance of deafness.

In conclusion, our data confirm a frequency of $2 \%$ for the A1555G mutation and its role in NSHL; however, the pathogenicity of all the other mtDNA variants encountered should be established: the variability of the frequency in different haplogroups, the occurrence in normal hearing individuals and the correlation with other conditions and mutations should be taken into account; thus, further genetic and functional studies are required in order to define their possible additional correlation with NSHL and/or aminoglycoside-induced HL.

\section{Acknowledgements}

The present study was supported by 'Ospedale Infantile e Pie Fondazioni Burlo Garofolo e dott. Alessandro ed Aglaia de Manussi’ Trieste.

\section{References}

1. Morton CC: Genetics, genomics and gene discovery in the auditory system. Hum Mol Genet 11: 1229-1240, 2002.

2. Jacobs HT, Hutchin TP, Käppi T, Gillies G, Minkkinen K, Walker J, Thompson K, Rovio AT, Carella M, Melchionda S, Zelante L, Gasparini P, Pyykkö I, Shah ZH, Zeviani M and Mueller RF: Mitochondrial DNA mutations in patients with postlingual, nonsyndromic hearing impairment. Eur J Hum Genet 13: 26-33, 2005.

3. Martini A: Genetica della Funzione Uditiva Normale e Patologica. Edizioni Omega, Torino, 2006.

4. Li Z, Li R, Chen J, Liao Z, Liao Z, Zhu Y, Qian Y, Xiong S, Heman-Ackah S, Wu J, Choo DI and Guan MX: Mutational analysis of the mitochondrial $12 \mathrm{~S}$ rRNA gene in Chinese pediatric subjects with aminoglycoside-induced and non-syndromic hearing loss. Hum Genet 117: 9-15, 2005.

5. Sinnathuray AR, Raut V, Awa A, Magee A and Toner JG: A review of cochlear implantation in mitochondrial sensorineural hearing loss. Otol Neurotol 24: 418-426, 2003.

6. Ballana E, Morales E, Rabionet R, Montserrat B, Ventayol M, Bravo O, Gasparini P and Estivill X: Mitochondrial 12S rRNA gene mutations affect RNA secondary structure and lead to variable penetrance in hearing impairment. Biochem Biophys Res Commun 341: 950-957, 2006.

7. Gürtler N,Schmuziger N,Kim Y,Mhatre AN,Jungi Mand Lalwani AK: Audiologic testing and molecular analysis of $12 \mathrm{~S}$ rRNA in patients receiving aminoglycosides. Laryngoscope 115: 640-644, 2005.

8. Scaglia F, Hsu CH, Kwon H, Bai RK, Perng CL, Chang HM, Dai P, Smith EO, Whiteman DA, Feigenbaum A, Gropman A and Wong LJ: Molecular bases of hearing loss in multi-systemic mitochondrial cytopathy. Genet Med 8: 641-652, 2006.

9. Chen JN, Ho KY and Juan KH: Sensorineural hearing loss in MELAS syndrome - case report. Kaohsiung J Med Sci 14: 519-523, 1998 .

10. Matsunaga T, Kumanomido H, Shiroma M, Ohtsuka A, Asamura K and Usami S: Deafness due to A1555G mitochondrial mutation without use of aminoglycoside. Laryngoscope 114: 1085-1091, 2004.

11. Simdon J, Watters D, Bartlett S and Connick E: Ototoxicity associated with use of nucleoside analog reverse transcriptase inhibitors: a report of 3 possible cases and review of the literature. Clin Infect Dis 32: 1623-1627, 2001.

12. Bravo O, Ballana E and Estivill X: Cochlear alterations in deaf and unaffected subjects carrying the deafness-associated A1555G mutation in the mitochondrial 12S rRNA gene. Biochem Biophys Res Commun 344: 511-516, 2006.

13. Rodriguez-Ballesteros M, Olarte M, Aguirre LA, Galan F, Galan R, Vallejo LA, Navas C, Villamar M, Moreno-Pelayo MA, Moreno F and del Castillo I: Molecular and clinical characterisation of three Spanish families with maternally inherited non-syndromic hearing loss caused by the $1494 \mathrm{C}->\mathrm{T}$ mutation in the mitochondrial 12S rRNA gene. J Med Genet 43: e54, 2006. 
14. Young WY, Zhao L, Qian Y, Li R, Chen J, Yuan H, Dai P, Zhai S, Han D and Guan MX: Variants in mitochondrial tRNAGlu, tRNAArg, and tRNAThr may influence the phenotypic manifestation of deafness-associated 12S rRNA A1555G mutation in three Han Chinese families with hearing loss. Am J Med Genet A 140: 2188-2197, 2006.

15. Prezant TR, Agapian JV, Bohlman MC, Bu X, Oztas S, Qiu WQ, Arnos KS, Cortopassi GA, Jaber L, Rotter JI, Shohat M and Fischel-Ghodsian N: Mitochondrial ribosomal RNA mutation associated with both antibiotic-induced and non-syndromic deafness. Nat Genet 4: 289-294, 1993.

16. Bacino C, Prezant TR, Bu X, Fournier P and Fischel-Ghodsian N: Susceptibility mutations in the mitochondrial small ribosomal RNA gene in aminoglycoside induced deafness. Pharmacogenetics 5: 165-172, 1995.

17. Li R, Xing G, Yan M, Cao X, Liu XZ, Bu X and Guan MX: Cosegregation of C-insertion at position 961 with A1555G mutation of mitochondrial 12S rRNA gene in a large Chinese family with maternally inherited hearing loss. Am J Med Genet A 124A: 113-117, 2004.

18. Yoshida M, Shintani T, Hirao M, Himi T, Yamaguchi A and Kikuchi K: Aminoglycoside-induced hearing loss in a patient with the 961 mutation in mitochondrial DNA. ORL J Otorhinolaryngol Relat Spec 64: 219-222, 2002.

19. Zhao H, Li R, Wang Q, Yan Q, Deng JH, Han D, Bai Y, Young WY and Guan MX: Maternally inherited aminoglycoside-induced and nonsyndromic deafness is associated with the novel C1494T mutation in the mitochondrial $12 \mathrm{~S}$ rRNA gene in a large Chinese family. Am J Hum Genet 74: 139-152, 2004.

20. Reid FM, Vernham GA and Jacobs HT: A novel mitochondrial point mutation in a maternal pedigree with sensorineural deafness. Hum Mutat 3: 243-247, 1994.

21. Fischel-Ghodsian N, Prezant TR, Fournier P, Stewart IA and Maw M: Mitochondrial mutation associated with nonsyndromic deafness. Am J Otolaryngol 16: 403-408, 1995.

22. Tiranti V, Chariot P, Carella F, Toscano A, Soliveri P, Girlanda P, Carrara F, Fratta GM, Reid FM, Mariotti C and Zeviani M: Maternally inherited hearing loss, ataxia and myoclonus associated with a novel point mutation in mitochondrial tRNA ${ }^{\mathrm{Ser}(\mathrm{UCN})}$ gene. Hum Mol Genet 4: 1421-1427, 1995.

23. Verhoeven K, Ensink RJ, Tiranti V, Huygen PL, Johnson DF, Schatteman I, Van Laer L, Verstreken M, Van de Heyning P, Fischel-Ghodsian N, Zeviani M, Cremers CW, Willems PJ and Van Camp G: Hearing impairment and neurological dysfunction associated with a mutation in the mitochondrial tRNA ${ }^{\text {Ser(UCN) }}$ gene. Eur J Hum Genet 7: 45-51, 1999.

24. Majamaa K, Moilanen JS, Uimonen S, Remes AM, Salmela PI, Kärppä M, Majamaa-Voltti KA, Rusanen H, Sorri M, Peuhkurinen KJ and Hassinen IE: Epidemiology of A3243G, the mutation for mitochondrial encephalomyopathy, lactic acidosis, and strokelike episodes: prevalence of the mutation in an adult population. Am J Hum Genet 63: 447-454, 1998.

25. Van den Ouweland JM, Lemkes HH, Ruitenbeek W, et al: Mutation in mitochondrial tRNA(Leu)(UUR) gene in a large pedigree with maternally transmitted type II diabetes mellitus and deafness. Nat Genet 1: 368-371, 1992.

26. Casano RA, Johnson DF, Bykhovskaya Y, Torricelli F, Bigozzi M and Fischel-Ghodsian N: Inherited susceptibility to aminoglycoside ototoxicity: genetic heterogeneity and clinical implications. Am J Otolaryngol 20: 151-156, 1999.
27. Tang HY, Hutcheson E, Neill S, Drummond-Borg M, Speer M and Alford RL: Genetic susceptibility to aminoglycoside ototoxicity: how many are at risk? Genet Med 4: 336-345, 2002.

28. Li R, Greinwald JH Jr, Yang L, Choo DI, Wenstrup RJ and Guan MX: Molecular analysis of mitochondrial 12S rRNA and tRNA ${ }^{\text {Ser(UCN) }}$ genes in paediatric subjects with non-syndromic hearing loss. J Med Genet 41: 615-620, 2004.

29. Berrettini S, Forli F, Passetti S, Rocchi A, Pollina L, Cecchetti D, Mancuso M and Siciliano G: Mitochondrial non-syndromic sensorineural hearing loss: a clinical, audiological and pathological study from Italy, and revision of the literature. Biosci Rep 28: 49-59, 2008.

30. Lingala HB and Sankarathi Penagaluru PR: Role of connexin 26 (GJB2) \& mitochondrial small ribosomal RNA (mt 12S rRNA) genes in sporadic \& aminoglycoside-induced non syndromic hearing impairment. Indian J Med Res 130: 369-378, 2009.

31. Hutchin TP and Cortopassi GA: Mitochondrial defects and hearing loss. Cell Mol Life Sci 57: 1927-1937, 2000.

32. Zheng J, Ji Y and Guan MX: Mitochondrial tRNA mutations associated with deafness. Mitochondrion 12: 406-413, 2012.

33. Konings A, Van Camp G, Goethals A, Van Eyken E, Vandevelde A, Ben Azza J, Peeters N, Wuyts W, Smeets H and Van Laer L: Mutation analysis of mitochondrial DNA 12SrRNA and tRNASer(UCN) genes in non-syndromic hearing loss patients. Mitochondrion 8: 377-382, 2008.

34. Herrnstadt C, Elson JL, Fahy E, Preston G, Turnbull DM, Anderson C, Ghosh SS, Olefsky JM, Beal FM, Davis RE and Howell N: Reduced-median-network analysis of complete mitochondrial DNA coding-region sequences for the major African, Asian, and European haplogroups. Am J Hum Genet 70: 1152-1171, 2002.

35. Neefs JM, Van de Peer Y, De Rijik P, Goris A and De Wachter R: Compilation of small ribosomal subunit RNA sequences. Nucleic Acids Res 19 Suppl: 1987-2015, 1991.

36. Del Castillo FJ, Rodriguez-Ballesteros M, Martin Y, Arellano B, Gallo-Terán J, Morales-Angulo C, Ramirez-Camacho R, Cruz Tapia M, Solanellas J, Martinez-Conde A, Villamar M, Moreno-Pelayo MA, Moreno F and del Castillo I: Heteroplasmy for the $1555 \mathrm{~A}>\mathrm{G}$ mutation in the mitochondrial $12 \mathrm{~S}$ rRNA gene in six Spanish families with non-syndromic hearing loss. J Med Genet 40: 632-636, 2003.

37. Elstner M, Schmidt C, Zingler VC, Prokisch H, Bettecken T, Elson JL, Rudolph G, Bender A, Halmagyi GM, Brandt T, Strupp M and Klopstock T: Mitochondrial 12S rRNA susceptibility mutations in aminoglycoside-associated and idiopathic bilateral vestibulopathy. Biochem Biophys Res Commun 377: 379-383, 2008.

38. Li X, Fischel-Ghodsian N, Schwartz F, Yan Q, Friedman RA and Guan MX: Biochemical characterization of the mitochondrial tRNA $^{\text {Ser(UCN) }}$ T7511C mutation associated with nonsyndromic deafness. Nucleic Acids Res 32: 867-877, 2004.

39. Campos Y, Martín MA, Rubio JC, Gutiérrez del Olmo MC, Cabello A and Arenas J: Bilateral striatal necrosis and MELAS associated with a new T3308C mutation in the mitochondrial ND1 gene. Biochem Biophys Res Commun 238: 323-325, 1997. 